\title{
Matemos as Barbies, de Selva Almada
}

Paula Yódice

\section{Matemos as Barbies}

Não gosto das Barbies

com seus peitinhos levantados

e as nádegas

como dois gominhos de tangerina

que lhes saem por trás.

Não gosto de seu cabelo platinado

nem do seu carrão rosa

nem da cara esticada do Ken

com seu arzinho de estudante

de barrados no baile.

As Barbies são tontas bonequinhas

de pussy afeitada

que perseguem em rollers

a uns bonecos seriados

filhos bastardos de David Husselthorf

e sonham se casar com eles

em uma tarde radiante

e poder ao fim ser legalmente

adúlteras

trincadas fodidas de pé

por um latin lover alugado

e gritar

I'm coming 
I'm coming

I'm coming

com vozinha quebrada de soprano.

Também não me enganam as Barbies

que moram em pequenas casas

de estilo Hooper tom pastel

e quando a tarde cai

bebem chá gelado junto a um Ken

de camisa xadrez e jeans apertado

sentados num balanço

com um lassie aos pés.

As Barbies nunca são mães:

tias ou baby sitters

passeiam carrinhos de bebê por idílicos parques

onde não são permitidos play mobils

nem tamagochis

nem raquíticas imitações da indústria

nacional.

Parques onde crescem tamarindos

e abetos e groselhas

e pulam coelhos, esquilos e renas

e embora nunca chova

sempre tem um arco-íris desenhado no céu.

À noite

de nurse a mulher fatal

as Barbies bebem bloody mary

sob uma lua de cherry

sem Prince.

De braços dados

como as meninas do Girondo

rebolam a bunda aos tarados

que esquentam suas orelhas

em um inglês atravessado

"que chamam de spanenglisl," 
cuja verborragia inclui

transa sudaca por um boquete

dessa boquita pintada

cerveja em lata e um hot dog.

Elas riem

não mordem o anzol.

De braços dados passeando sua histeria

conhecem a regra:

tem que chegar virgem à cama do Ken.

Acabam a noite

sozinhas em seus quartos

fumando cigarros importados

escrevendo em seus diários

que um boy latino

fez elas pecarem

com essa comichão aí embaixo.

Escrevem:

não seria mal outro Vietnã

para limpar as ruas desses demônios

undergorund.

$\mathrm{Na}$ verdade

queriam é falar:

eu invejo você, Melanie Griffith

mas se confortam

antes de dormir

I love Ken

I love Ken

I love Ken.

As Barbies têm vergonha

da ideia progressista da fábrica

de jogar para o mundo

uma irmã paralítica e um cunhado gay.

Felizmente

prevaleceu o consumo sensato

do american way

e tiraram eles do mercado. 
No país das Barbies tudo é...

você sabe

e não tem espaço para essas agitações tontas

chamadas Bósnia, embargo ou HIV.

Com tantos problemas

que incomodam o pessoal do Melrose Place

elas não dão conta:

entendam.

Já é muito

ensinar suas donas como ser bonecas

e entender

que no mundo

sempre é melhor

andar armadas com um bom par de tetas

que ser infelizes portas adentro

e a abrir as pernas só quando for chegado o momento.

Por um instante quase as entendo

mas eu já disse:

não gosto das Barbies.

Se as Barbies pudessem envelhecer

seriam distintas senhoras alcoólatras

presidiriam fundações de arte

com seu nome

se pudessem ter um nome

e continuariam se apaixonando por Ken

agiornado segundo as tendências da moda

mas sempre Ken

bronzeado e malhado

o sonho dourado de toda menina.

Sempre Ken:

de dia encoxando empregadas filipinas

à noite metido em estranhos affairs

Por isso: matemos as Barbies

a culpa não é delas.

Matemos as Barbies:

descansem seus vãos corpinhos em paz. 


\section{Matemos a las Barbies}

No me gustan las Barbies

con sus tetitas paradas

y las nalgas

como dos gajitos de mandarina

que les salen por detrás.

No me gusta su pelo platinado

ni su deportivo rosa

ni el estirado de Ken

con su aire de prepa

a lo beverly noventa dos diez:

Las Barbies son tontas muñequitas

de pussy afeitada

que persiguen en rollers

a muñecos seriados

hijos bastardos de David Husselthorf

y sueñan casarse con ellos

en un mediodía radiante

y poder por fin ser legalmente

adúlteras

trincadas de pie

por un latin lover alquilado

y gritar

ai camin

ai camin

ai camin

con vocecita quebrada de soprano.

Tampoco me engañan las Barbies

que viven em casitas

estilo Hooper color pastel

y cuando la tarde cae

beben te helado junto a un Ken

de camisa leñadora y jean apretado

sentados en un columpio

con un lassie a los pies. 
Las Barbies nunca son madres:

tías o baby sitters

pasean cochecitos por idílicos parques

donde no se permiten play mobils

ni tamagotchis

ni esmirriadas imitaciones de la industria

nacional.

Parques donde crecen tamarindos

y abetos y grosellas

y brincan conejos, ardillas y renos

y aunque nunca llueve

siempre hay un arco iris dibujado en el cielo.

A la noche

de nurse a mujer fatal

las Barbies toman bloody mary

bajo una luna de cherry

sin Prince.

Tomadas del brazo

como las pibas de Girondo

les menean el culo a los mojados

que calientan sus orejas

en un inglés atravesado

"spanenglish que le llaman"

cuya verborragia incluye

un polvo sudaca por una mamada

de esa boquita pintada

cerveza en lata y un hot dog.

Ellas se ríen

no muerden el anzuelo.

Del brazo siguen paseando su histeria

conocen la regla:

hay que llegar virgen a la cama de Ken.

Terminan la noche

solas en sus cuartos

fumando cigarrillos importados 
escribiendo en sus diarios

que un boy hispano

las hizo pecar

de raras cosquillitas ahí abajo.

Escriben:

no vendría mal otro Vietnam

para librar las calles de esos demonios underground.

En realidad

querrían decir:

te envidio, Melanie Griffith

pero se convencen

antes de dormirse

ai lav Ken

ai lav Ken

ai lav Ken.

Las Barbies se averguenzan

de la idea progre de la fábrica

de echarles al mundo

una hermana paralítica y un cuñado gay.

Por suerte

primó el consumo sensato

del american way

y los borraron del mercado.

En Barbielandia todo es...

como tú sabes

y no hay sitio para esas tontas movidas

llámense Bosnia, bloqueo o HIV.

Con tantos problemas

como acucian a los de Melrose Place

ellas no pueden con todo:

entiéndanlo.

Ya es bastante

enseñar a sus dueñas a ser muñecas

a entender

que por el mundo 
siempre es mejor

andar muñidas de un buen par de tetas

a ser infelices puertas adentro

y a abrir las piernas solo llegado el momento.

Por un rato casi las entiendo

pero ya lo dije:

no me gustan las Barbies.

Si las Barbies pudiesen envejecer

serían distinguidas damas alcohólicas

presidiendo fundaciones de arte

con su nombre

si pudieran tener un nombre

y seguirían enamorándose de Ken

agiornado según las tendencias de la moda

pero siempre Ken

bronceado y musculoso

el sueño dorado de toda chica.

Siempre Ken:

de día correteando sirvientas filipinas

de noche enredado en extraños affaires.

Por eso: matemos a las Barbies

no es suya la culpa.

Matemos a las Barbies:

descansen sus vanos cuerpitos en paz.

\section{Nota da tradutora}

"Matemos a las Barbies" está no primeiro livro de Selva Almada (Entre Ríos, Argentina, 1973), Mal de muñecas (Carne Argentina, 2003), que reúne alguns poemas e um relato em prosa, acompanhado de ilustrações. Trata-se de um dos poucos textos publicados da autora que pertencem ao gênero lírico, onde já aparecem alguns pontos que se tornaram uma constante na sua narrativa posterior: o lugar da mulher e do homem no sistema patriarcal, a violência dos mandatos sociais nos corpos, as tensões fronteiriças nas misturas linguísticas e culturais.

Em efeito, o poema foca não só o objeto, mas o que ele representa. As Barbies condensam muitos sentidos. Por um lado, são brinquedos que moldam o imaginário das meninas em relação aos estereótipos que a sociedade propõe: 
serem belas, jovens, tontas, obedientes, caladas, não assumir o corpo como lugar do próprio prazer, mas para o conforto de outros que - não obstante - as fazem "pecar com essa comichão aí embaixo". A dupla moral de chegar virgem ao matrimônio para ganhar o título de esposa, enquanto o marido persegue empregadas domésticas (outros corpos de aluguel).

Por outra parte, essas bonecas são uma síntese do estilo de vida estadunidense que se exporta ao mundo globalizado: a camisa xadrez do Ken, a casa estilo Hooper, o hot dog, a necessidade de fabricar inimigos de guerra e de estereotipar a diversidade no outro; a irmã paralítica, o cunhado gay, em contraposição com a Barbie radiante. Ela tem vergonha de sair da mesma fábrica. E os "consumidores sensatos" entendem que nesse mundo não existe lugar para a alteridade. Será por isso que, ainda que existam as versões negras, muçulmanas, grávidas ou paralíticas, nunca são as que se aparecem em nossa imaginação quando nomeamos a Barbie? $\mathrm{O}$ que a faz original, se é fabricada em série?

Por que esse modelo de sujeito condensado em um pedaço de plástico com forma feminina adentrou tão fundo em nós? Como desconstruir esse modelo, senão com a morte?

A violência que convoca o título desse poema não é outra coisa além de um eco da violência que mora na imposição cultural, linguística e de gênero. Necessitamos dessas mortes para desconstruir-nos e reconstruir-nos como mulheres, como sudacas, como sujeitos com nome próprio, como alternativas aos corpos vazios, escassos de carne e pretensamente inócuos.

Escolhi traduzir esse poema por vários motivos: porque me impactou a primeira vez que o escutei sair da boca de uma professora querida; pela generosidade da autora em me permitir publicar o texto; porque sintetiza as distintas violências que carregamos habitualmente alguns sujeitos; porque me seduz a mistura idiomática que se atualiza cada vez que uma poeta constrói novamente sua voz ao intercalar outras.

Essa tradução procura respeitar a cadência do espanhol e sua estrutura gramatical, mas também a intrusão de palavras em inglês e em espanglês, destacadas em itálico na versão do poema em português, embora no original não se diferenciem do resto do texto. Se interpretar é traduzir (inclusive na mesma língua) mas, além disso, trair, espero que a minha versão transmita nos novos leitores a potência com a que vibro cada vez que leio o poema. 